\title{
Inquiry and Experiential Mixed Teaching Method Is Effective Way to Cultivate High-Quality Innovative Talents
}

\author{
S. H. Zhong and W. L. Zhou
}

\begin{abstract}
By analyzing the necessity and training objectives of high-quality innovative talents training, this paper expounds the restriction of traditional education on the cultivation of high-quality innovative talents. On the basis of analyzing the relationship between inquiry and experiential mixed teaching method and high-quality innovative talents, it shows that inquiry and experiential teaching methods is an effective way to train high-quality innovative talents. On the basis of analyzing the connotation of inquiry and experiential mixed teaching method, the applicable environment of this teaching mode is expounded. The theory and method of human resource management is one of the important contents that constitute the integrity of industrial engineering disciplines. The course of human resource management in industrial enterprises is of great significance to the cultivation of innovative thinking of students majoring in industrial engineering in higher education. Taking the teaching method of human resource management in industrial enterprises as an example, this paper expounds the application process of inquiry and experiential mixed teaching method.
\end{abstract}

Index Terms - Innovative talent, inquiry and experiential teaching method, teaching reform.

\section{INTRODUCTION}

At the seventh meeting of the Central Financial and Economic Leading Group, Xi Jinping said that talent was the foundation of innovation and the core element of innovation. Essentially the drive of innovation is talent-driven. High-quality innovative talents are needed in production, construction, management and other fields. The "high-quality and innovative" composite talents who between the "academic and theoretical" research talents with rich theoretical foundations and the "professional and skilled" talents with excellent engineering skills are the types of talents. China urgently needs these types of talents in the future [1]. And also, the cultivation of these talents is the historical mission of higher education. How to cultivate these talents is one of the most severe tests that higher education faces at present. In this connection, on the basis of analyzing the training methods of high-quality innovative talents, the author took the practice of teaching reform of human resource management in industrial enterprises as an example, and then

Manuscript received March. 2. 2019; revised July 3, 2019. This work was supported in part by the Fundamental Research Funds for the Central Universities 2010QZ04 and the Undergraduate Education Reform Project at School Leve J170111.

The authors are with the Department of School of Energy and Mining Engineering, China University of Mining \& Technology (Beijing), Beijing, China (e-mail: zhsh@cumtb.edu.cn,cumtbzwl@qq.com). expounds that the inquiry and experiential mixed teaching method is an effective way to cultivate innovative talents.

\section{Cultivation OF High-Quality InNOvative Talents}

\section{A. The Necessity of Training High-Quality Innovative Talents}

President Xi Jinping repeatedly pointed out that talents were the first resource for national development, and innovation was the first driving force. If China wants to be strong and resurgent, it must develop science and technology vigorously. Major scientific and technological innovations are important and powerful tools of the country, which must be firmly controlled by the country itself and must rely on self-reliance and independent innovation [2]. The level and speed of knowledge innovation are the key factors of economic growth. The ability to grasp and apply information is the core of economic competition. While governing the source of knowledge and innovation depends on the talents with innovation consciousness, innovative spirit and innovative ability. Such talents are the advantage and foundation of a country's sustainable development as well as valuable resources. Accelerating the cultivation of innovative talents is the only way to survive and develop in the fierce international competition [3].

\section{B. The Traditional Teaching Mode Restricts the Cultivation of Innovative Talents Final Stage}

The traditional education mode of our country, which centered on teachers, focusing on classroom teaching, is an indoctrinating teaching. Students cram knowledge points from the textbook in order to pass the exam, so the best effect can be achieved is to memorize the knowledge heritage of predecessors, which cannot cultivate students' innovation consciousness, innovation ability and innovation spirit. At present, the main problem of talent training in China is that it overemphasizes students' memorization of knowledge points and passing examinations, and the cultivation of students' ability in independent thinking, comprehensive analysis and problem solving are lacking, as well as the cultivation of innovation consciousness, innovative thinking, innovative ability and innovative spirit. Therefore, it is difficult to cultivate high-quality innovative talents.

III. THE RELATIONSHIP BETWEEN INQUIRY AND EXPERIENTIAL TEACHING METHOD AND HIGH-QUALITY TALENTS TRAINING 


\section{A. The Connotation of Inquiry and Experiential Mixed Teaching Method}

Inquiry and experiential mixed teaching method mainly combines the inquiry teaching method and the experiential teaching method. Inquiry teaching method is a kind of teaching method that takes independent learning and cooperative discussion of students as the premise, current textbooks as the basic inquiry content, and the world and real life around students as the reference object. It provides students with the opportunity to freely express, question, research and discuss, allowing students to try various forms of activities, such as individual, group and collective, and apply what they have learned to solve practical problems [4]. The teaching thought of inquiry teaching method is mainly manifested in carrying out learning and exploration activities around problems, using scientific thinking to design boldly, emphasizing on learning in exploration, thinking in the process of acquiring knowledge and giving play to students' subjective initiative. Experiential teaching is a kind of teaching activity that stimulates students' learning experience through the personal experience and practical participation of students in the process of practical problem solving, and then trains and promotes the practical thinking through the operation and generation of learning experience [5]. Inquiry and experiential mixed teaching method is the combination of the two teaching methods. From the teacher's point of view, it is a teaching form that makes students understand and construct knowledge and develop ability in the process of experiencing by creates actual or repeated experience situations and opportunities based on the cognitive characteristics and rules of students. These situations and opportunities not only need to present or reproduce the teaching content, but also need to constantly guide students to discover problems, find ways to solve problems, and finally achieve the goal of solving problems. From the perspective of students, it focuses on the improvement of students' interest in learning and the satisfaction of curiosity. In addition to advocating students' personal experience and feelings, it is also necessary to discuss and study the existing problems and pay attention to the cultivation of students' comprehensive ability driven by innovation.

\section{B. Inquiry and Experiential Teaching Method Provides Favorable Conditions for the Cultivation of High-Quality Innovative Talents}

The training objective of high-quality innovative talents is determined according to the knowledge, ability and quality structure required by high-quality innovative talents, including: 1) the ability to clearly think, express and write; 2) the ability to reason systematically in a critical manner 3 ) the ability to form concepts and solve problems; 4) the ability to think independently; 5) the ability to dare to innovate and work independently; 6) the ability to work with others; 7) ) the ability to judge what means a thorough understanding of something; 8) the ability to identify important things and trivial things, persistent things and short-lived things; 9) be familiar with different ways of thinking; 10) the depth of knowledge in a certain field; 11) the ability to observe the relevance of different disciplines, cultures, and ideas; 12) the ability to have a lifetime of learning [6]. The targeted training objectives clearly direct the cultivation of high-quality innovative talents.

Inquiry and experiential mixed teaching method makes students understand and construct knowledge, develop ability and divergent thinking in the process of exploring problems, according to the cognitive characteristics and laws of students. This process has cultivated students' abilities to think independently, analyze problems and solve problems comprehensively. It has also cultivated students' abilities to summarize, arrange and build new projects creatively with the knowledge and methods learned, so as to cultivate students' innovative consciousness and innovative thinking. Inquiry and experiential teaching methods has stimulated students' enthusiasm for learning, increased their interest in learning, mobilized the enthusiasm of students to explore and be brave in innovation, and maximally satisfied students' further thirst for knowledge and continuous innovation spirit, so as to achieve the training objectives of high-quality innovative talents.

\section{The Applicable Environment of Inquiry and Experiential Mixed Teaching Method}

Inquiry and experiential mixed teaching method is a student-centered teaching mode, whose purpose is to cultivate innovative talents. It is inevitable that there are some shortcomings in this teaching mode. First of all, the inquiry and experiential mixed teaching method is currently still lack of sufficient support conditions. According to the usual teaching experience, this teaching mode often requires more support from external conditions such as more time, a small class with about 5-20 students, more experimental funds and social family concept. Therefore, it is difficult to carry out in primary and secondary schools, especially under the current educational requirements. Secondly, the inquiry and experiential mixed teaching method is difficult to give consideration to students at different levels of development. Facing all students is one of the new curriculum concepts. Due to the problem setting and student personality, it is difficult to take care of each student. What's worse, it will even sever the enthusiasm of individual students, and the effect is counterproductive. Thirdly, the inquiry and experiential mixed teaching method is more challenging and more likely to fail, which requires teachers and students to have better psychological endurance. It is inevitable for teachers and students to experience setbacks, detours and even failures in the process of carrying out exploratory experiments. Many of these feelings and experiences are of great educational value to the growth of students. However, once the teacher cannot make appropriate guidance, it is easy to make students lose the enthusiasm and initiative to learn. Finally, due to the openness of this teaching mode, it is very difficult to control the teaching process, which brings great difficulties to the teaching organization of teachers. If the classroom is not well organized, it will affect the teaching effect, and even fail to reach the teaching goal.

According to the above disadvantages of the inquiry and experiential mixed teaching method, in order to give full play to its innovation, the corresponding applicable conditions are proposed: Firstly, this teaching mode is more suitable for higher education. Higher education is divided into three forms: 
undergraduate, postgraduate (including master and doctoral), and junior college [7]. Students at this level have a certain knowledge background and have enough time at their disposal. In addition, the class size of general higher education is relatively small, and the school has abundant experimental resources. These features all provide the necessary conditions for the realization of the effects of inquiry and experiential mixed teaching method. Secondly, the teachers need to have some experience. If teachers have only a partial understanding of inquiry and experiential mixed teaching method, it will be difficult to carry out teaching. By the means such as material objects, wall charts, stories and music, teachers can create a pleasant learning atmosphere, build a bridge between the knowledge students have known and the teaching content in class, and arouse students' desire to participate. Finally, this teaching mode is suitable for the courses that are more technical, more operational, more practical and more research.

\section{FORMATION AND APPLICATION OF INQUIRY AND EXPERIENTIAL TEACHING METHOD}

\section{A. The Forming Process of Inquiry and Experiential Teaching Method}

Industrial Engineering, originating from the United States, is a discipline that designs, improves and implements the integrated system composed of relevant personnel, materials, equipment, energy and information [8]. It adopts systematic, professional and scientific thinking and methods, through the organic combination of engineering technology and management science, to form a comprehensive subject based on mathematics, operations research, economics, management, engineering and system science, computer science and modern manufacturing engineering [9]. The composition of industrial engineering is shown in Fig. 1:

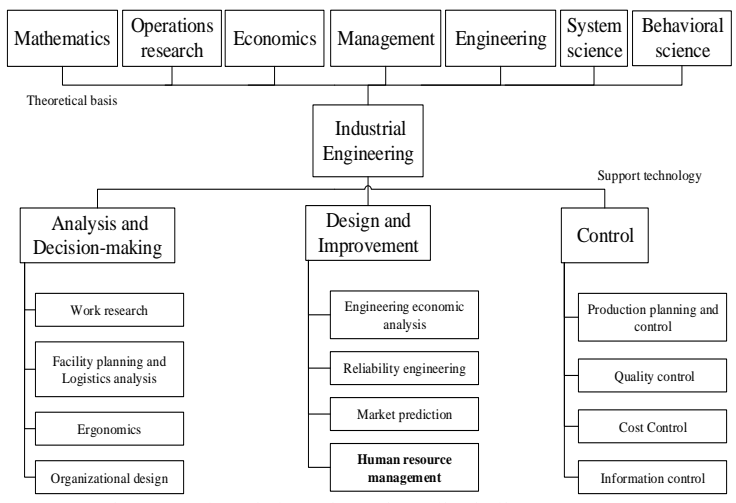

Fig. 1. Industrial engineering discipline system.

Human resource management takes human resources in the business activities of enterprises as the research object. Its purpose is to promote the sustainable development of enterprises through scientific business decisions and practical activities. The theory and method of human resource management become one of the important contents of the integrity of Industrial Engineering. According to various technical features and functions of industrial engineering, the supporting technologies of industrial engineering can be divided into three categories: design and improvement, analysis and decision-making, and control. In the industrial engineering system, human resource management is not only closely related to the behavioral science which as its basic theory, but also the important foundation of industrial engineering. Its main goal is to solve the problems in recruitment, appointment, evaluation and assessment of human resources, so as to make the appointment and removal, transfer, promotion, training and other work fair and reasonable, enhance the creativity and initiative of employees, improve work efficiency, and obtain good economic benefits.

Human Resource Management in industrial enterprises is of great significance to cultivate students' innovative thinking. However, with the advent of the information age, the traditional teaching method of instructor teaching and student learning has been broken by the era of information explosion. It is imperative to innovate teaching means and explore new teaching methods. The Inquiry and Experiential Teaching Method accords with the characteristics of Human Resources Management in industrial enterprises, which could contribute to the cultivation of students' innovative consciousness and innovative thinking by highlighting students' the subjective position in teaching and stimulating their interest in learning. Combined with the teaching objectives and characteristics of Human Resources Management in industrial enterprises, the forming process of Inquiry and Experiential Teaching Method is shown in Fig. 2:

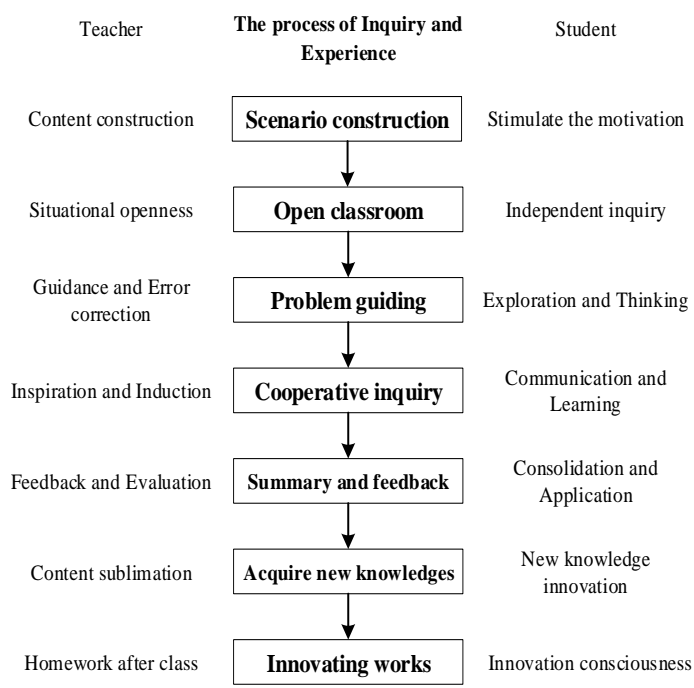

Fig. 2. The formation process diagram of inquiry and experiential teaching method.

Scenario construction. Under the Inquiry and Experiential Teaching Method, firstly according to the content and purpose of the syllabus, teachers ask to students the questions that need to be explored with the form of actual cases before class. The questions should be based on the students' foundation and features, designed by combination with the key points and difficulties of the course. And the selection of the questions should logical and reasonable.

Open classroom. Exploring in an open question situation. The openness of situation is beneficial to motivate students' interest and thinking, which helps students to provide more information and expand the capacity of information when they responding.

Problem guiding. Creating an inspiring situation to motivate students to think actively. Setting questions in the 
situation according to the teaching objectives, designing and selecting the reference questions in a targeted manner. In order to achieve the purpose of letting students learn independently, teachers should guide students to discover problems by themselves. When students have something do not understand, they can instruct appropriately and induce the direction of exploration. Then give students appropriate time to think, because the length of waiting time will influence the effect of response. An enough thinking time is conducive for student to provide complete and deep answers. Reducing anxiety and tension. The lengthy waiting time not only can make the classroom rhythm loose, but also can make student burnout and loss of enthusiasm and initiative [10].

Cooperative inquiry. Let students communicate the inquiry results and discuss the raised question and the universal ambiguous understanding, question and solve doubts boldly in the cooperation. The format of discussions is not limited. Students could divide into groups or gather together to discuss according to their own will. Reach to the combination of teacher guidance and student self-inquiry, the combination of knowledge transfer and problem solving and the combination of single thinking and creative thinking.

Summary and feedback. Teachers review, conclude and summarize based on the results of the discussion, focusing on the intrinsic connection of knowledge and paying attention to the scope and depth of the discussion. Teachers should complement the key and difficult points, which are ignored by students, and sublimate question's extensive knowledge. Students should be praised for their independent thinking ability, clear logical thinking and systematic reasoning ability, as well as the ability to dare to innovate and work independently, and the ability to work with others; These have a good effect on improving students' learning motivation, enhancing their innovative consciousness and thinking. Evaluation summary and timely feedback are the sublimation of classroom teaching and the deepening of teaching objectives, as well as the key point to consolidate knowledge and correct students' understanding.

Acquire new knowledges. The learning process is transformed from the traditional "absorption, storage, and reproduction" to "exploration, research, and creation", which reflects the learning process of "raise problems - analyze problems - solve problems - innovate knowledge. Through the teacher's summary, students sublimate their views on problems and realize the process of innovating knowledge.

Innovating works. Teachers designing the task that more comprehensive and closer to the actual work than the pre-class and while-class project tasks on the basis of completive classroom tasks. And release the task to the student by means of information technology to encourage students to be divergent and flexible, cultivate students' innovation consciousness, stimulate students' independent and explore learning interest [11]. Through the independent training to stimulate students thinking, promote the further improvement of knowledge and skills, and expand students' innovation consciousness, innovation ability and innovation spirit.

\section{B. Application of Inquiry and Experiential Teaching in} Human Resources Courses of Industrial Enterprises
Case analysis can be used in several chapters of the syllabus of Human Resources Management in industrial enterprises. When it is explaining the performance management, let students analyze the causes of social laziness with the case of Ringermann's "drawing experiment", which can stimulate students' learning enthusiasm, give students' self-reflective ability, and then evaluate the importance of management; The case of "Performance Management of Tianlong aviation food company" covers a large number of knowledge points. By reading, analyzing and researching this case, the students are guided to think independently and participate in the discussion actively. The classroom atmosphere is very active. In the exchange and discussion, students could understand and master the knowledge more deeply, and also could tap deeper knowledge. After the discussion in the classroom, the students were asked to write an extended written analysis of the questions discussed. In this material, most students can think widely and organize their language in a structured manner. The students could not only understand the knowledge, but also exercise their ability to analyze and solve problems independently. The case analysis is an inquiry and experiential teaching method, which can exert the students' ability of independent thinking, clear logical thinking and systematic reasoning skill. The whole process is centered around students. Students find question, ask questions and solve problems, then teachers guide students approaching the theoretical knowledge and finally propose a theoretical system. It provides a favorable environment for cultivating students' innovative thinking, innovative consciousness and innovative ability [12].

Scenario simulation is to simulate a real work environment and require students to deal with work affairs according to their responsibilities in the work situation. In the "Recruitment and Employment" section, students are organized to simulate a scenario of recruitment and interviews and teachers briefly explain the scenarios that need to be simulated before class. The actors are not simple to perform or imitate, but they must act as in a day-to-day practical situation with resourceful and flexible adaptability. It will use non-leader group discussions, group interviews, psychological tests and other methods to evaluate job seekers. At the end, according to the performance of candidates and interviewers in the scene, it will analyze the general procedure for recruiting employees from the perspective of performing students and watching students. Teachers need to appropriately guide students' explore direction, control classroom time, and students need to explore the screening techniques that how to make reasonable choices and applications of psychological tests, interviews, and evaluation centers. Scenario simulation reflects the student-centered teaching philosophy, which enhances the enthusiasm of learning and is conducive to the improvement of students' comprehensive ability, such as planning, organization, communication, exploring, response, and ability to withstand stress. Through this practical experience, students can experience the powers and responsibilities of practical work and improve their ability to innovate and work independently.

\section{CONCLUSION}


The cultivation of high-quality innovative talents is the necessary way for talent training in China. This paper takes the human resource management in industrial enterprises as an example, changes the traditional cramming teaching method, and has analyzed that the inquiry and experiential teaching method has a promoting effect and important significance for cultivating students' innovative consciousness, innovative thinking and innovative ability, which provides effective means for education and teaching reform. Practice has proved that inquiry and experiential teaching methods is an effective way to cultivate high-quality innovative talents.

\section{CONFLICT OF INTEREST}

The authors declare no conflict of interest.

\section{AUTHOR CONTRIBUTIONS}

Shuheng Zhong conducted the research and wrote the paper; Wenlong Zhou translated the paper; all authors had approved the final version.

\section{REFERENCES}

[1] Y. S. Zhou, H. H. Yi, and X. L Tang., "Practical teaching reform based on the cultivation of high-quality innovative talents," China Metallurgical Education, vol. 4, pp. 83-85, 2017.

[2] J. P. Xi, General Secretary Xi Jinping's Important Speech Reader, Beijing: People's Publishing House. 2014.

[3] Q. F. Meng, J. H. Lu, Z. Z. Wang, Y. G. Chen, T. B. Ding, H. Y. Guo, L. R. Teng, and L. Y. Liu, "Exploratory experiment is an effective way to cultivate innovative talents," Laboratory Research and Exploration, vol. 1, pp. 85-88, 2004.

[4] C. S. Zhang "Inquiry: The ideal choice for classroom teaching reform," Educational Theory and Practice, vol. 11, pp. 39-42, 2001.

[5] L. Chen, "The design research of experiential teaching method," Ph.D. dissertation, Southwest University, China, 2008.

[6] Y. F. Yan, "University: how to cultivate innovative talents - Also on the successful experience of famous American universities," China Higher Education Research, vol. 12, pp. 3-9, 2006.

[7] G. S. Wang and H. Y. Li, "The status quo, problems and countermeasures of the hierarchical structure of higher education in China," Higher Education Research of Heilongjiang, vol. 1, pp. 8-10, 2006.
[8] X. Y. Wang, S. L. Lin, "Two deficiencies in China's industrial engineering education," Journal of Agricultural Mechanization Research, vol. 6, pp. 288-288, 2005.

[9] Y. Dai, Z. Y. Wu, and Z. J. Ma, "Status quo and development trend of industrial engineering discipline system," Journal of Southwest Jiaotong University: Social Science Edition, vol. 3, no. 2, pp. 62-66, 2002.

[10] M. Zhang, "Discussion on interactive teaching in human resource management Course," Education and Occupation, vol. 17, pp. 151-152, 2010.

[11] Y. J. Wang, "Reflections on the teaching mode of innovative management courses in the "Internet + " era - Review of teaching caused by human resource management class discussion," Journal of Inner Mongolia Normal University (Educational Science Edition), vol. 31, no. 7, pp. 69-72, 2018.

[12] G. $\mathrm{Li}$, "Student-centered reform of the teaching model of human resources management," Education and Occupation, vol. 17, pp 154-155, 2014.

Copyright $(92019$ by the authors. This is an open access article distributed under the Creative Commons Attribution License which permits unrestricted use, distribution, and reproduction in any medium, provided the original work is properly cited (CC BY 4.0).

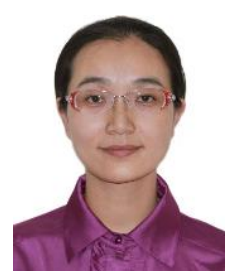

Shuheng Zhong was born in 1978, Jiangsu, China. She received her BA, MA and $\mathrm{PhD}$ at Yangzhou University, and China University of Mining and Technology (Beijing) in 2000, 2003 and 2011. She served as an associate professor at China University of Mining and Technology (Beijing) since 2013.

Mainly research and teaching of Zhong is in resources development and planning, mining system engineering, industrial engineering and other aspects. Zhong received scientific and educational awards including the Science and Technology Award by China Coal Industry Science and Technology. Zhong has authored 2 books and over 20 refereed journal papers.

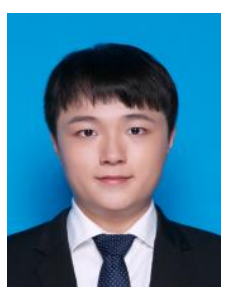

Wenlong Zhou was born in Henan, China in May 1997. He is currently studying at the China University of Mining and Technology in Beijing, mainly engaged in research in the field of industrial engineering. During the school period, he has won the national scholarship and other honors. 